\title{
The Joint Contributions of Maternal Depression and Infant Negative Emotionality to Maternal Sensitivity to Infant Distress
}

\author{
Charlotte A. M. Cecil, Department of Psychology, King's College London \\ Andrew Pickles, Institute of Psychiatry, King's College London \\ Jonathan Hill, University of Reading \\ Helen Sharp, University of Liverpool
}

\begin{abstract}
Correspondence should be sent to: Helen Sharp, Department of Psychological Science, Institute of Psychology, Health and Society, Eleanor Rathbone Building, Bedford Street South Liverpool, United Kingdom L69 7ZA, Tel: +44(0) 1516505490 (Wirral Child Health \& Development Study Base), E-mail: hmsharp@liv.ac.uk
\end{abstract}

Acknowledgements: This study was funded by a grant from the UK Medical Research Council, G0400577. None of the authors has a competing financial interest in relation to the work described. We are very grateful to all participating families and to the research staff who contributed to this work. We also thank Wirral University Teaching Hospital NHS Foundation Trust, Cheshire and Wirral Partnership NHS Foundation Trust and Wirral Community NHS Foundation Trust for their support. 


\begin{abstract}
Little is known about the role of infant emotionality and its interplay with maternal depression in the prediction of maternal sensitivity and whether these emotion-laden processes in mother and infant may be particularly relevant to sensitivity to distress. We studied 260 first time mothers and their infants, recruited into a general population prospective study during pregnancy. Infant negative emotionality was assessed at 5 weeks using the Neonatal Behavioral Assessment. At 29 weeks maternal sensitivity was observed and mothers were interviewed for DSM Major Depressive episodes since birth. Controlling for potential confounders, neither maternal depression nor infant negative emotionality independently predicted maternal sensitivity, but the interaction between them was statistically significant $(p=.01)$. Increasing infant negative emotionality predicted decreasing maternal sensitivity to distress, only in mothers who experienced an episode of Major Depressive Disorder during the postnatal period. This effect was not seen for sensitivity to non-distress, although the test of the difference between the effects was not statistically significant $(\mathrm{p}=.07)$. Maternal postnatal depression may create an affective and cognitive vulnerability to the effects of frequent intense infant negative emotions. These findings have implications for our understanding of psychological processes underlying parental sensitivity, and hence for early interventions.
\end{abstract}




\section{INTRODUCTION}

Ever since the pioneering work on parent-infant attachment carried out by Bowlby (1969) and Ainsworth (e.g. Ainsworth, Blehar, Waters, \& Wall, 1978), maternal sensitivity, defined as the contingent, interested and warm responding to infant cues (Bornstein \& Tamis-Lemonda, 1997), has been a focus of studies of the early infant environment. Sensitive responsiveness during the first year of life has been associated with a range of emotional, affective and cognitive outcomes that are important for fostering positive parent-child relationships and adaptive child development (Bornstein, Tamis-LeMonda, Hahn, \& Haynes, 2008; Landry, Smith, MillerLoncar, \& Swank, 1997; Landry, Smith, \& Swank, 2006; Paavola, Kunnari, \& Moilanen, 2005). Despite this, knowledge of factors that may explain variability in mothers' capacity to respond sensitively to their infant is limited (McElwain \& Booth-Laforce, 2006; Thompson, 1997). They are likely to include accurate interpretation of infant cues, effective emotion regulation, and appropriate responding based on context and the infant's developmental stage (Leerkes, Nayena Blankson, \& O'Brien, 2009). In the present study we examined the role of maternal depression and infant negative emotionality, both factors that may undermine these processes.

\section{Maternal depression and sensitivity}

Maternal depression over the first months of life has been a major focus of research into the determinants of maternal sensitivity because of its multiple effects on emotion regulation, attributional processes, cognition and concentration (Aldao, Nolen-Hoeksema, \& Schweizer, 
2010; Gelfand \& Teti, 1990; Hoffman, Crnic, \& Baker, 2006, Campbell et al., 2004).

Differences between depressed and non-depressed mothers have been identified in the neural circuits activated during responses to their own infant crying (Laurent \& Ablow, 2012), and depressed mothers have been found to respond less contingently and consistently to their infant, to have slower reactions to infant cues, and to display more negative affect than non-depressed mothers (Downey \& Coyne, 1990). In the NICHD study of child care, a longitudinal study of over 1000 mother-child dyads, elevated trajectories of maternal depressive symptoms over several years were found to be associated with lower maternal sensitivity (NICHD, 1999a, Campbell et al 2004, Campbell, Matestic, von Stauffenberg, Mohan, \& Kirchner, 2007). However maternal depression is associated with multiple other risks, such as socioeconomic deprivation, partner relationship problems and comorbid psychiatric disorders, and a number of studies have failed to find an effect of maternal depression on sensitive parenting after accounting for potential confounds (e.g. Campbell et al., 1995). Associated risks may also modify the association between maternal depression and sensitivity (Gelfand \& Teti, 1990, Donovan, Leavitt, \& Walsh, 1998; Murray et al., 1996). Several studies have provided evidence that maternal depression is associated with decreased maternal sensitivity only in the presence of co-occurring risk factors in the wider environment, such as poverty and marital discord (e.g. De Wolff \& Van Ijzendoorn, 1997; Gelfand \& Teti, 1990; Martins \& Gaffan, 2000). For example, Crockenberg and Leerkes (2003a) found that depression per se did not predict sensitivity, but that a significant reduction in maternal sensitivity was observed when maternal depression was accompanied by partner aggression. Maternal depression may also confer risk in the presence of maternal personality disorder (Conroy, Marks, Schacht, Davies,\& Moran, 2010) or other psychiatric disorders (Carter, Garrity-Rokous, Chazan-Cohen, Little, \& Briggs-Gowan, 2001). 


\section{Infant negative emotionality may elicit lower maternal sensitivity}

Socialization processes are dynamic and bidirectional, involving both parent and child. Parental behaviours may increase risk for negative child outcomes and, equally, child characteristics may elicit certain parental responses over time ( Cecil, Barker, Jaffee, \& Viding, 2012). Irritable infants show more marked, frequent and aggressive displays of distress in response to aversive stimuli and greater resistance to soothing attempts (Riese, 1987). They may therefore provide fewer social reinforcers for contingent warm parenting than other infants, over time lowering sensitivity (Bridgett et al., 2009). While some studies have reported a significant relationship between infant negative emotionality and maternal sensitivity (e.g. Crockenberg, 1981; Seifer, Schiller, Sameroff, Resnick, \& Riordan, 1996; Susman-Stillman, Kalkoske, Egeland, \& Waldman, 1996), others have failed to find associations between these two variables (e.g. McElwain \& Booth-Laforce, 2006; Murray et al., 1996; Stams, Juffer, \& van Ijzendoorn, 2002). In addition, many of the studies finding associations have been cross-sectional, thereby limiting inferences about the direction of effects. Co-occurring risk factors are again likely to be important. Elevated infant proneness to distress is associated with a range of psychosocial risks including partner conflict, social isolation, financial instability and maternal psychopathology (e.g. Papousek \& von Hofacker, 1998). These may better account for associations between infant temperament and maternal sensitivity, or parenting may be affected by negative infant emotionality only under conditions of high-risk (see Crockenberg \& Leerkes, 2003b, for a review). There may also be specificity in the conditions under which sensitivity is affected. For example Van den Boom and Hoeksma (1994) found that mothers of irritable infants who came 
from more socially deprived backgrounds were less sensitive to their infants cues, but only in situations where the infant was calm, rather than in distress.

\section{The role of infant and parent factors on maternal sensitivity: Unique contribution or interactive effect?}

It is possible that, rather than acting as distinct predictors of maternal sensitivity, maternal depression and infant negative emotionality interact with one another to decrease sensitive responsiveness, as a result of low maternal resources coupled with a temperamentally difficult child (Crockenberg, 1986). This notion is consistent with the findings of Pauli-Pott, Mertesacker, Bade, Bauer, and Beckmann (2000), who examined the role of observed and maternal reports of infant negative emotionality and maternal hopelessness in observed maternal sensitivity at 4 months. While neither infant negative emotionality nor maternal hopelessness was independently associated with maternal sensitivity, the interaction was highly significant. Increasing maternal hopelessness was associated with decreasing sensitivity only in mothers with infants who were high in negative emotionality. This study used a cross-sectional design and so the associations could have arisen, at least in part, from effects of maternal sensitivity on infant emotionality, however the findings add to the case for the examination of the prospective contributions of infant temperament and maternal depression to maternal sensitivity.

\section{Distinguishing Domains of Maternal Sensitvity}

There is increasing evidence that the developmental consequences of maternal sensitivity may differ depending on whether parents are responding to infant distress or to playful or exploratory behaviours (Goldberg, Grusec, \& Jenkins, 1999; Thompson, 1997). In situations 
where the infant is experiencing fear, pain or distress, sensitive maternal responses may encourage the development of regulatory capacities as well as providing the infant with an 'internal working model' of the caregiver as a reliable, responsive, and effective source of comfort (Bowlby, 1969). By contrast, sensitive responding to an infant's attempts to manipulate toys or show objects to the parent (i.e. non-distress) may contribute to the infant's sense of agency and capacity for exploration, but not be salient for the development of emotional regulation.

In support of this distinction, McElwain and Booth-Laforce (2006) found that sensitivity to infant distress, but not sensitivity to non-distress, predicted parent-child attachment quality during early infancy. Moreover, Leerkes Blankson and O'Brien (2009) found only sensitivity to distress to be associated with fewer child behaviour problems and greater socio-emotional adjustment, while Davidov and Grusec (2006) reported that only maternal responsiveness to infant distress predicted a range of outcomes related to emotional regulation and empathy-related behaviours. Rodriguez and colleagues (2005) contrasted high-stress and playful experimental settings and found that only maternal unresponsiveness during the high stress task was associated with later self-regulatory skills in toddlers. On the other hand, a number of studies examining cognitive outcomes have reported that only sensitivity in playful interactions (i.e. non-distress) was associated with cognitive development, attention span and symbolic play (Bornstein \& Tamis-Lemonda, 1997; Murray et al., 2008).

If maternal sensitivity to distress enhances affect regulation in the child, and sensitivity to non-distress supports cognitive development and other low affect functions, might there be an equivalent difference in processes underpinning these contrasting competences in mothers? 
Crockenberg and Leerkes (2003b) hypothesised that this may be the case. Maternal depression could increase a mother's vulnerability to experience negative affect when her infant is crying, and especially where the infant is prone to frequent and intense displays of distress. Hence the combination of maternal depression and infant proneness to distress would reduce maternal sensitivity to distress. Sensitivity to non-distress by contrast might be lowered by competing demands that may interfere with the mother's ability to respond to her infant's signals for attention during neutral or positive situations. These might arise from pressures such as economic hardship or lack of support for day to day coping.

In this study we used a longitudinal design to address two hypotheses. Firstly, infant emotionality and maternal depression interact to predict maternal sensitivity. Secondly, this association is specific to sensitivity to distress.

\section{METHOD}

\section{Design}

The participants were members of the Wirral Child Health and Development Study, a prospective epidemiological longitudinal cohort drawn from consecutive first time mothers who booked for antenatal care at 12 weeks gestation between 12/02/2007 and 29/10/2008. All mothers were required to be aged 18 years or above at the time of consent. The booking clinic was administered by the Wirral University Teaching Hospital which was the sole provider of universal prenatal care on the Wirral Peninsula, Merseyside, UK. The study uses a two stage stratified design in which a larger general population sample of first-time mothers was recruited 
in pregnancy (extensive sample) and from which a sub-sample was drawn for more intensive assessment (intensive sample). All families in the extensive sample follow a brief assessment protocol while those in the intensive subsample receive a more time-consuming, detailed and more frequent assessment regime. Further details can be found in a previous publication (Sharp, et al., 2012). The extensive sample of 1233 consenting mothers with surviving singleton babies had a mean age at recruitment of 26.8 years (s.d.5.8, range 18-51). Forty eight women (3.9\%) described themselves as other than White British. Socioeconomic conditions on the Wirral range between the deprived inner city and affluent suburbs.

All participants scoring above the high risk stratum defined as an above threshold score for psychological abuse towards or from their partner at 20 weeks gestation, were eligible for inclusion in the intensive sample together with a random sample from the remaining low scoring participants. Of 316 women with surviving singleton births selected for the intensive sub-sample, $51 \%$ were drawn from the women with high psychosocial risk and $49 \%$ from those with low psychosocial risk. Of this intensive sub-sample, 278 infants were observed for negative emotionality at 5.2 (s.d. 2.1) weeks ('5 weeks'). At 29.1 (s.d. 3.1) weeks ('29 weeks'), mothers were observed for maternal sensitivity $(n=272)$ and interviewed for a recent history of depression $(n=260)$. Mothers in the intensive subsample were slightly older than those in the original extensive sample, mean age 27.9 years (s.d. 6.2, range 18-51).

\section{Ethics}

Approval for the procedures was obtained from the Cheshire North and West Research Ethics Committee (UK). The study was introduced to the women by clinic midwives who asked for their agreement to be approached by study research midwives when they attended for 
ultrasound scanning at 20 weeks gestation. After complete description of the study, written informed consent was obtained by the study midwives who then administered questionnaires and an interview in the clinic.

\section{Measures}

Each of the measures of infant irritability, maternal sensitivity, and maternal depression was rated independently, by different assessors.

\section{Stratification.}

Participants completed a 20 item Psychological Abuse questionnaire (Moffitt, Caspi, Margolin et al., 1997) at 20 weeks gestation which assessed presence or absence of different psychologically abusive behaviors in the partner relationship, including humiliating, demeaning or threatening utterances, over the past year. The scale generates a total from 20 no-yes items (coded as 0 absent, 1 present). Participants rated their own behaviors towards their partner and then their partner's behaviors towards them. This measure has been shown to yield large correlations between self and partner informant reports (Moffitt et al., 1997). The psychological abuse variable used here was the highest of the partner to participant and participant to partner scores for each family.

\section{Confounders.}

To control for presence of contextual factors that could act as potential confounders in the variables of interest, we included in our analyses three socio-environmental factors that have been previously associated with maternal depression, infant negative emotionality and maternal sensitivity. These were demographic, social deprivation and marital satisfaction variables 10 
(Bradley \& Corwyn, 2002; Crockenberg, 1986; Murray et al., 1996; Paulussen-Hoogeboom, Stams, Hermanns, \& Peetsma, 2007).

Demographic measures were self-reported marital status as 'married', 'cohabiting' or 'single' and mothers age. Socioeconomic status was determined using the revised English Index of Multiple Deprivation (IMD) (Noble et al., 2004) based on data collected from the UK Census in 2001. According to this system, postcode areas in England are ranked from most deprived (i.e. IMD of 1) to least deprived (i.e. IMD of 32,482) based on deprivation in seven domains: income, employment, health, education and training, barriers to housing and services, living environment and crime. All mothers were given IMD ranks according to the postcode of the area where they lived. Marital satisfaction at the time of the assessment of maternal sensitivity at 29 weeks was assessed using the 3 item Kansas Marital Satisfaction Scale (KMSS) which has been widely used and has good psychometric properties (Schumm et al., 1983, Graham et al., 2009).

\section{Predictors.}

\section{Maternal depression.}

Mothers were interviewed using the Schedule for Affective Disorders and Schizophrenia - Lifetime Version (SADS-L; Spitzer \& Endicott 1975) for any episodes of DSM-IV Major Depressive Disorder (American Psychiatric Association 1984) from birth to the time of the assessment of maternal sensitivity (29 weeks post-partum). We used an investigator based version with established reliability and validity for DSM disorders (Harrington et al., 1988). 
Inter-rater reliability between the interviewers for depression, based on 30 assessments, was high $(\mathrm{kappa}=.84)$.

\section{Infant Negative Emotionality.}

The Neonatal Behavioural Assessment (NBAS) was administered to the intensive sample at 5 weeks after birth. The NBAS is a standardized measure designed to assess orienting, motor and emotion regulatory processes during the first weeks of life (Brazelton \& Nugent 1995, Lester et al . 1976). It is conducted by a trained administrator who carries out, in a prescribed sequence, a range of manoeuvres designed to elicit the infant's optimal orienting and motor performance, and emotional responses to mildly aversive procedures such as undressing or being brought from lying to sitting. Ratings are generally made by the administrator from memory immediately after the assessment. This limits the scope for determining inter-rater reliability so in this study the assessments were video recorded using four cameras placed to obtain a comprehensive picture of infant responses. The NBAS coding method yields a total of 27 scores which have been previously reduced in factor analytic studies, yielding variously three to nine factors (McCollam et al., 1997). In common with several previous studies (e.g. Crockenberg 1981), negative emotionality was assessed using a scale of infant irritability which was the mean of 3 NBAS scales, 'rapidity of build up', 'peak of excitement', and 'irritability'.

\section{Outcomes.}

\section{Maternal Sensitivity.}

Maternal sensitivity and infant negative mood were assessed at 29 weeks post-natal with 12 
a widely used 15 minute standard laboratory based procedure (NICHD, 1999a). Mothers were asked to play with their infants as they would at home, for 7 minutes with toys supplied by the mother, and for 8 minutes with a standard set of toys provided by the experimenter. Maternal sensitivity to distress and non-distress were each rated on a global 5-point scale, ranging from 1 (not at all characteristic) to 5 (highly characteristic). Sensitivity to distress captured the extent to which the mother responded to her infant's cries, frets or distress in a consistent, timely, and appropriate manner. Sensitivity to non-distress captured the extent to which the mother observed and responded in a well-paced and appropriate manner to her infant's social gestures, expressions, and signals of non-distress. Infant negative mood was rated using the NICHD coding scheme which uses a global 5-point scale, ranging from 1 (not at all characteristic) to 5 (highly characteristic). The scale assesses the extent to which the child cried, fussed, frowned, tensed his/her body, threw 'temper tantrums' or otherwise expressed their discontentment during the 15 minute observation period. Training on the NICHD rating scales was provided by an investigator from the NICHD Network. Three raters, blind to the other measures, coded sensitivity from video recordings. Each rater achieved good inter-rater reliability for maternal sensitivity on a subset of 30 assessments (ICCs $.83-.89$ ).

\section{Statistical analysis}

In the initial step of the analysis we ran bivariate correlations to test associations between the variables of interest. This enabled us to examine the strength and direction of associations between our predictor and outcome variables, as well as determining whether the contextual factors selected as covariates were significantly related to maternal sensitivity to distress and non-distress. The formal analysis was required to address two issues to do with sample selection. 13 
The first concerned the explicit sample design, namely the stratification by the level of psychological abuse reported at 20 weeks of pregnancy. This was accounted for by the inclusion of psychological abuse as a covariate in the main regression model. The second issue concerned the implicit selection that occurs for the measurement of sensitivity to distress, since this is unavailable for those with infants who show no distress during observation. This was addressed by analyzing sensitivity to distress as one dependent variable in a set of regression models with correlated errors, the other two dependent variables being sensitivity to non-distress and an additional variable measured during the mother-infant observation, infant negative mood. This last variable is not directly of interest in this study but was associated with both the observed values of sensitivity to distress and sensitivity to non-distress, $r(197)=-.29, p<.001$ and $r$ $(258)=-.15, p<.05$, respectively and with whether the sensitivity to distress score was unavailable $\left(\chi^{2}=226.80, d f=1, N=260, p<.001\right)$. No association between child negative mood and any of the predictor, stratification and confounder variables was found and since it was included only to help account for the implicit sample selection we do not present findings for this dependent variable.

In the final step of the analysis, we ran a multivariable regression which enabled us to establish whether maternal depression and infant negative emotionality affected the maternal sensitivity via independent or interactive effects and, since the three separate regression equations (i.e. one for each outcome variable) were estimated within the same model, also enabled us to test whether predictor coefficients for sensitivity to distress were different from those for sensitivity to non-distress. To provide robustness to non-normality the regression analysis was bootstrapped 10,000 times from which we obtained bias corrected $95 \%$ confidence intervals. The regression analysis was conducted using Mplus vs 6.1.1. 


\section{RESULTS}

\section{Preliminary correlational analysis}

Of the 260 women assessed at 29 weeks with the SADS-L, $42(16 \%)$ had met DSM-IV criteria for Major Depressive Disorder since the birth of their infants. However, only 3 met criteria at the time of the 29 weeks assessment. Bivariate correlations between the study variables are presented in Table 1 . Sensitivity to infant distress was positively associated with sensitivity to non-distress. Maternal sensitivity to both distress and non-distress were negatively correlated with single status and psychological abuse. Lone mothers had significantly lower sensitivity scores than those cohabiting with a partner and mothers experiencing psychological abuse had lower sensitivity scores than mothers who did not. All potential confounding variables included in the study correlated with the two dimensions of maternal sensitivity. Both maternal age and partner satisfaction were positively associated with maternal sensitivity to distress and non-distress, while higher deprivation was negatively correlated with maternal sensitivity. Neither maternal depression nor infant irritability at 5 weeks was significantly correlated with sensitivity to distress and non-distress at 29 weeks.

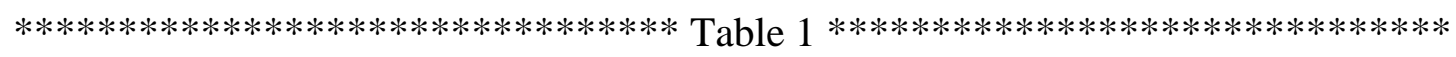




\section{Multivariate multiple regression analysis}

Results from the multivariate multiple regression are displayed in Table 2 . The model estimated was saturated with parameters (or just identified), therefore fit statistics are not reported.

\section{Sensitivity to distress.}

Psychological abuse significantly predicted lower maternal sensitivity to distress, but the effect of cohabiting status was non-significant. However, maternal age remained a significant predictor of sensitivity to distress, with older mothers being more likely to respond more sensitively to their infant's distress cues. Neither major depressive episode nor infant irritability independently predicted maternal sensitivity to distress. However there was a significant interaction between maternal depression and infant irritability in the prediction of maternal sensitivity to distress $(B=-.46, S E=.02, p=.01)$, above and beyond the effect of confounder factors. The interaction is shown in Figure 1. From this graph it is possible to see that within the non-depressed group, maternal sensitivity to distress changed little with increasing levels of infant irritability. By contrast, among mothers who experienced at least one episode of Major Depressive Disorder between birth and 29 weeks, increasing infant irritability at 5 weeks was associated with lower sensitivity to distress at 29 weeks.

\section{Sensitivity to non-distress}

Neither psychological abuse nor cohabiting status independently predicted sensitivity to non-distress. However older maternal age and greater partner satisfaction significantly associated with increased maternal sensitivity to non-distress, and deprivation had a marginal negative 
effect on sensitivity to non-distress. As with sensitivity to distress, neither maternal depression nor infant irritability independently predicted maternal sensitivity to non-distress. The interaction term of maternal depression and infant irritability, while similar in direction to that for sensitivity to distress, was substantially smaller and was not significant.

************************************ Table $2 * * * * * * * * * * * * * * * * * * * * * * * * * * * * * * * * * *$

$* * * * * * * * * * * * * * * * * * * * * * * * * * * * * * * *$ Figure $1 * * * * * * * * * * * * * * * * * * * * * * * * * * * * * * * * * *$

\section{Testing the difference between interaction terms}

We carried out a model comparison analysis to establish whether the interaction effect of maternal depression and infant irritability on sensitivity was stronger for sensitivity to distress than sensitivity to non-distress. The two measurements of sensitivity used the same scale which enabled us to compare a model where both interaction coefficients were allowed to vary freely with one where the interaction coefficients were held to be of equal size. It is important to note, however, that because differences in the amount of data available were present (i.e. 91 of the infants in the sample did not become distressed during assessment so ratings of sensitivity to distress were not available for them) the test may not have had optimal statistical power to detect differences in the effect size of the two interaction terms. Despite this, results showed that the regression coefficient of the interaction term predicting sensitivity to distress was more than two times larger than that failing to predict sensitivity to non-distress. The difference between the two interaction terms was found to be marginally significant $\Delta \chi^{2}(1)=3.21, p=.07$. 


\section{DISCUSSION}

In a UK general population sample, DSM Major Depression in mothers over the first 29 weeks following the birth of their babies modified the prospective association between infant negative emotionality at 5 weeks, and maternal sensitivity at 29 weeks. Increasing infant negative emotionality was associated with lower maternal sensitivity only among mothers experiencing postnatal depression. This association held after accounting for a range of potential confounders, some of which, such as partner dissatisfaction also predicted lower maternal sensitivity. Sensitivity to distress, but not sensitivity to non-distress, was predicted by infant negative emotionality among depressed mothers. The test of the difference in the effects was close to conventional statistical significance $(\mathrm{p}=.07)$.

We found that postnatal depression was not associated with maternal sensitivity, which is consistent with evidence reviewed earlier, both that confounders may better account for associations, and that associations are commonly found only in interaction with other risks. The one large-scale study that has reported main effects of maternal depression on sensitivity, after accounting for potential confounders, covers several years (NICHD 1999b) and so the findings are not directly comparable to those reported here at 29 weeks. Consistent evidence from prospective studies predicting maternal sensitivity from infant temperament is lacking, making it difficult to judge the comparability of our findings with others. Our finding that infant irritability predicted maternal sensitivity only in the presence of maternal depression is consistent with several reports that both maternal depression and infant negative emotionality are associated with lowered maternal sensitivity only in the presence of other risks.

The strengths of the study include that infant negative emotionality and the presence of maternal depression were assessed in the period prior to the observation of maternal sensitivity, 
and each was assessed and coded independently of the other. The use of direct observations for infant negative emotionality and maternal sensitivity, and of an investigator rated measure of maternal depression, eliminated maternal biases from the measures. We accounted for the selective missingness of sensitivity to distress ratings which has not been done in previous studies. A limitation of the study is that the episodes of maternal major depression occurred at varying times over the 29 weeks period from birth, and there were too few to examine the possible effect of temporal proximity of episode and sensitivity. Only three mothers met DSM diagnosis for major depressive episode at the 29 week assessment, and so this is a study of recent, rather than current post-natal depression.

As we observed earlier, the test of the difference in strengths of association of the interaction between maternal depression and infant irritability with sensitivity to distress and to non-distress was not statistically significant. However, we found evidence of a significant interaction only in relation to sensitivity to distress, and so we discuss specifically mechanisms that may underlie the link between maternal depression, infant negative emotionality and sensitivity to distress. Sensitivity to distress, unlike sensitivity to non-distress, has the distinctive quality that not only is the parent called upon to respond warmly and contingently, but also to bring about a change in the infant's emotional state. The success of each cycle of interaction is therefore likely to depend both on the extent to which the infant quietens, and the parent's perception of whether she has been effective. The infant who cries frequently, and who does not quieten readily in response to a mother's efforts, may provide a mother with repeated experiences of failure, exacerbating learned helplessness and self-devaluative cognitions seen in depression (Teasdale \& Cox, 2001). Support for such processes has come from a series of experimental studies. Donovan (1981) exposed mothers of young infants to contrasting 
conditions in which button pressing either terminated infant cry or had no effect. In subsequent trials when both groups were able to terminate infant crying, those with the previous experience of inescapable cry were slower to respond. Donovan and Leavitt (1985) showed that the effect of inescapable cry was greater if mothers were told that the infant had been irritable and fussy since birth than if they were given a description of a placid baby. Thus it seemed that both the immediate experience of mothers' effectiveness in terminating crying and their attributions of the infant's temperament contributed to learned helplessness. Further experiments provided evidence for the role of maternal psychosocial factors. Mothers' ability to detect a change of frequency in infant crying was predicted by their levels of depression and marital conflict (Donovan, Leavitt, \& Walsh, 1998).

Maternal age, cohabiting status, socioeconomic deprivation and partner satisfaction were included in the analyses as possible confounders because they had previously been associated with the variables of interest (e.g. Crockenberg, 1986; Gelfand \& Teti, 1990). Although they are not the focus of this report the associations shown in the present study suggest some avenues for future research. In particular increasing maternal age was strongly associated with higher sensitivity to distress and to non-distress. We did not set out to test whether further variables might explain the association of age with sensitivity and so we interpret it cautiously. It is possible that, compared to younger mothers, older first-time mothers are better equipped to respond sensitively to their infant as they are more likely to have greater psychological, emotional and environmental resources at their disposal. Older mothers may possess more patience and maturity as a result of their accumulated life experiences, have obtained a higher educational level and benefit from more favourable external circumstances, such as greater financial security and stability in their careers and home life (Sutcliffe, Barnes, Belsky, Gardiner, 20 
\& Melhuish, 2012). In turn, these factors may facilitate sensitive responding and improve quality of parent-child interactions (Fergusson \& Woodward, 1999, Fergusson \& Lynskey, 1993). Lower partner satisfaction was associated with less sensitivity to non-distress. This is consistent with the proposal referred to earlier, of Crockenberg and Leerkes (2003), that sensitivity to nondistress may be reduced where a parent's cognitive and attentional resources are diverted away from the child by multiple demands in day to day life, such as might be the case in the absence of a supportive partner.

Taken together the findings highlight the value of differentiating between sensitivity to distress and to non-distress, both to enhance consistency across studies, and to improve our understanding of the underlying processes. Understanding the joint contributions of infant emotionality and maternal mental health problems to sensitivity to distress has the potential to provide a more precise foundation for the development of interventions. At the same time, our knowledge of the specific social attributional, emotion regulatory and executive function processes in maternal sensitivity remains rudimentary and should provide a focus for future research. 


\section{REFERENCES}

Ainsworth, M. D. S., Blehar, M. C., Waters, E., \& Wall, S. (1978). Patterns of attachment: A psychological study of the strange situation. Patterns of Attachment: A Psychological Study of the Strange Situation.

Aldao, Amelia, Nolen-Hoeksema, Susan, \& Schweizer, Susanne. (2010). Emotion-regulation strategies across psychopathology: A meta-analytic review. Clinical Psychology Review, 30(2), 217-237. doi: http://dx.doi.org/10.1016/j.cpr.2009.11.004

American Psychiatric Association (1994). Diagnostic and Statistical Manual of Mental Disorders (DSM-IV ) (4th edn). American Psychiatric Association: Washington, DC.

Belsky, J., Bakermans-Kranenburg, M. J., \& Van Ijzendoorn, M. H. (2007). For better and for worse: Differential susceptibility to environmental influences. Current Directions in Psychological Science, 16(6), 300-304.

Bornstein, M. H., \& Tamis-Lemonda, C. S. (1997). Maternal responsiveness and infant mental abilities: Specific predictive relations. Infant Behavior and Development, 20(3), 283-296.

Bornstein, M. H., Tamis-LeMonda, C. S., Hahn, C. S., \& Haynes, O. M. (2008). Maternal Responsiveness to Young Children at Three Ages: Longitudinal Analysis of a Multidimensional, Modular, and Specific Parenting Construct. Developmental Psychology, 44(3), 867-874.

Bowlby, J. (1969). (Vol. 1): Attachment. New York: Basic Books.

Bradley, R. H., \& Corwyn, R. F. (2002) Socioeconomic status and child development. Annual review of psychology, 53(1), 371-399. 
Brazelton, T.B. \& Nugent, J.K. (1995) Neonatal Behavioral Assessment Scale, MacKeith Press, London.

Bridgett, D. J., Gartstein, M. A., Putnam, S. P., McKay, T., Iddins, E., Robertson, C., . . . Rittmueller, A. (2009). Maternal and contextual influences and the effect of temperament development during infancy on parenting in toddlerhood. Infant Behavior and Development, 32(1), 103-116. doi: 10.1016/j.infbeh.2008.10.007

Campbell, S. B., Brownell, C. A., Hungerford, A., Spieker, S. J., Mohan, R., \& Blessing, J. S. (2004). The course of maternal depressive symptoms and maternal sensitivity as predictors of attachment security at 36 months. Development and Psychopathology, $16(2), 231-252$.

Campbell, S. B., Cohn, J. F., \& Meyers, T. (1995). Depression in First-Time Mothers: MotherInfant Interaction and Depression Chronicity. Developmental Psychology, 31(3), 349357.

Campbell, S. B., Matestic, P., von Stauffenberg, C., Mohan, R., \& Kirchner, T. (2007). Trajectories of Maternal Depressive Symptoms, Maternal Sensitivity, and Children's Functioning at School Entry. Developmental Psychology, 43(5), 1202-1215.

Carter, A. S., Garrity-Rokous, F. E., Chazan-Cohen, R., Little, C., \& Briggs-Gowan, M. J. (2001). Maternal depression and comorbidity: Predicting early parenting, attachment security, and toddler social-emotional problems and competencies. Journal of the American Academy of Child and Adolescent Psychiatry, 40(1), 18-26.

Cecil, C. A. M., Barker, E. D., Jaffee, S. R., \& Viding, E. (2012). Association between maladaptive parenting and child self-control over time: cross-lagged study using a 
monozygotic twin difference design. The British Journal of Psychiatry. doi:

10.1192/bjp.bp.111.107581

Cohn, J. F., Matias, R., Tronick, E. Z., Connell, D. \& Lyons-Ruth, K. (1986). Face-to-face interactions of depressed mothers and their infants. New Directions for Child and Adolescent Development, 1986(34), 31-45. doi: 10.1002/cd.23219863405

Conroy, S., Marks, M. N., Schacht, R., Davies, H. A., \& Moran, P. (2010). The impact of maternal depression and personality disorder on early infant care. Social Psychiatry and Psychiatric Epidemiology, 45(3), 285-292. doi: 10.1007/s00127-009-0070-0

Crockenberg, S. B. (1981). Infant irritability, mother responsiveness, and social support influences on the security of infant-mother attachment. Child development, 52(3), 857865.

Crockenberg, S. B., \& Leerkes, E. M. (2003a). Parental acceptance, postpartum depression, and maternal sensitivity: Mediating and moderating processes. Journal of Family Psychology, 17(1), 80-93.

Crockenberg, S.B., \& Leerkes, E. (2003b). Infant negative emotionality, caregiving, and family relationships. Children's Influence on Family Dynamics: The Neglected side of Family Relationships.

Crockenberg, S. B. (1986). Are temperamental differences in babies associated with predictable differences in care giving? New Directions for Child and Adolescent Development, 1986(31), 53-73. doi: 10.1002/cd.23219863105

Davidov, M., \& Grusec, J. E. (2006). Untangling the links of parental responsiveness to distress and warmth to child outcomes. Child Development, 77(1), 44-58. 
De Wolff, M. S., \& Van Ijzendoorn, M. H. (1997). Sensitivity and Attachment: A Meta-Analysis on Parental Antecedents of Infant Attachment. Child Development, 68(4), 571-591.

Donovan, W. L. (1981). Maternal learned helplessness and physiologic response to infant crying. Journal of Personality and Social Psychology, 40(5), 919.

Donovan, W. L., \& Leavitt, L. A. (1985). Simulating conditions of learned helplessness: The effects of interventions and attributions. Child development, 594-603.

Donovan, W. L., Leavitt, L. A., \& Walsh, R. O. (1998). Conflict and depression predict maternal sensitivity to infant cries. Infant Behavior and Development, 21(3), 505-517. doi: http://dx.doi.org/10.1016/S0163-6383(98)90023-6

Downey, G., \& Coyne, J. C. (1990). Children of depressed parents: An integrative review. Psychological Bulletin, 108(1), 50-76.

Feldman, R., Granat, A., Pariente, C., Kanety, H., Kuint, J., \& Gilboa-Schechtman, E. (2009). Maternal Depression and Anxiety Across the Postpartum Year and Infant Social Engagement, Fear Regulation, and Stress Reactivity. Journal of the American Academy of Child and Adolescent Psychiatry, 48(9), 919-927.

Fergusson, D. M., \& Lynskey, M. T. (1993). Maternal age and cognitive and behavioural outcomes in middle childhood. Paediatric and Perinatal Epidemiology, 7(1), 77-91.

Fergusson, D. M., \& Woodward, L. J. (1999). Maternal age and educational and psychosocial outcomes in early adulthood. Journal of Child Psychology and Psychiatry and Allied Disciplines, 40(3), 479-489. doi: 10.1017/S0021963098003722

Gelfand, D. M., \& Teti, D. M. (1990). The effects of maternal depression on children. Clinical Psychology Review, 10(3), 329-353. doi: 10.1016/0272-7358(90)90065-I 
Goldberg, S., Grusec, J. E., \& Jenkins, J. M. (1999). Confidence in protection: Arguments for a narrow definition of attachment. Journal of Family Psychology, 13(4), 475-483. doi: 10.1037/0893-3200.13.4.475.

Graham, J.M., Diebels, K.J.,\& Barnow, Z.B. (2011). The reliability of relationship satisfaction: a reliability generalization meta-analysis. Journal of Family Psychology, 25(1):39-48.

Harrington, R., Hill, J., Rutter, M., John, K., Fudge, H., Zoccolillo, M. \& Weissman, M. (1988). The assessment of lifetime psychopathology: a comparison of two interviewing styles. Psychological Medicine 18, 487-493.

Hill, J., Murray, L., Leidecker, V., \& Sharp, H. (2008). The dynamics of threat, fear and intentionality in the conduct disorders: longitudinal findings in the children of women with post-natal depression. Philosophical Transactions of the Royal Society of London B Biological Sciences, 363(1503), 2529-2541.

Hoffman, C,, Crnic, K. A., \& Baker, J. K. (2006). Maternal Depression and Parenting: Implications for Children's Emergent Emotion Regulation and Behavioral Functioning. Parenting, 6(4), 271-295. doi: 10.1207/s15327922par0604_1

Landry, S. H., Smith, K. E., Miller-Loncar, C. L., \& Swank, P. R. (1997). Predicting cognitivelanguage and social growth curves from early maternal behaviors in children at varying degrees of biological risk. Developmental psychology, 33(6), 1040-1053.

Landry, S. H., Smith, K. E., \& Swank, P. R. (2006). Responsive parenting: Establishing early foundations for social, communication, and independent problem-solving skills. Developmental Psychology, 42(4), 627-642. 
Laurent, H. K., \& Ablow, J. C. (2012). A cry in the dark: depressed mothers show reduced neural activation to their own infant's cry. Social cognitive and affective neuroscience, $7(2), 125-134$.

Leerkes, E. M., Nayena Blankson, A., \& O'Brien, M. (2009). Differential effects of maternal sensitivity to infant distress and nondistress on social-emotional functioning. Child Development, 80(3), 762-775. doi: 10.1111/j.1467-8624.2009.01296.x

Lemola, S., Stadlmayr, W., \& Grob, A. (2009). Infant irritability: The impact of fetal alcohol exposure, maternal depressive symptoms, and low emotional support from the husband. Infant Mental Health Journal, 30(1), 57-81. doi: 10.1002/imhj.20203

Lester, B.M., Emory, E.K. \& Hoffman, S.L. (1976) A multivariate study of the effects of highrisk factors on performance on the Brazelton Neonatal Assessment Scale. Child Development., 47, 515-517.

Lovejoy, M. C., Graczyk, P. A., O'Hare, E. \& Neuman, G. (2000). Maternal depression and parenting behavior: A meta-analytic review. Clinical Psychology Review, 20(5), 561-592. doi: http://dx.doi.org/10.1016/S0272-7358(98)00100-7.

Martins, C., \& Gaffan, E. A. (2000). Effects of early maternal depression on patterns of infantmother attachment: A meta-analytic investigation. Journal of Child Psychology and Psychiatry, 41(6), 737-746. doi: 10.1017/S0021963099005958.

McCollam, K.M., Embretson, S.E., Mitchell, D.W. \& Horowitz, F.D. (1997) Using confirmatory factor analysis to identify newborn behavior structure in the NBAS. Infant Behavior and Development, 20(2), 123-131. 
McElwain, N. L., \& Booth-Laforce, C. (2006). Maternal sensitivity to infant distress and nondistress as predictors of infant-mother attachment security. Journal of Family Psychology, 20(2), 247-255. doi: 10.1037/0893-3200.20.2.247

Moffitt, T.E., Caspi, A., Margolin, G., Krueger, R.F., Magdol, L., Silva, P.A., \& Sydney, R. (1997). Do partners agree about abuse in their relationship? A psychometric evaluation of interpartner agreement. Psychological Assessment, 9(1), 47-56.

Murray, L., Hentges, F., Hill, J., Karpf, J., Mistry, B., Kreutz, M., .....Goodacre, T. (2008). The effect of cleft lip and palate, and the timing of lip repair on mother-infant interactions and infant development. Journal of Child Psychology and Psychiatry, 49(2), 115-123. doi: 10.1111/j.1469-7610.2007.01833.x

Murray, L., Stanley, C., Hooper, R., King, F., \& Fiori-Cowley, A. (1996). The role of infant factors in postnatal depression and mother-infant interactions. Developmental Medicine and Child Neurology, 38(2), 109-119.

Musser, E. D., Kaiser-Laurent, H., \& Ablow, J. C. (2012). The neural correlates of maternal sensitivity: An fMRI study. Developmental Cognitive Neuroscience, 2(4), 428-436.

Najman, J. M., Williams, G. M., Nikles, J., Spence, S., Bor, W., O'Callaghan, M., . . Andersen, M. J. (2000). Mothers' mental illness and child behavior problems: Cause-effect association or observation bias? Journal of the American Academy of Child and Adolescent Psychiatry, 39(5), 592-602.

NICHD. (1999a). Chronicity of maternal depressive symptoms, maternal sensitivity, and child functioning at 36 months. NICHD Early Child Care Research Network. Developmental psychology, 35(5), 1297-1310. 
NICHD Early Child Care Research Network (1999b). Child care and mother-child interaction in the first 3 years of life. Developmental Psychology, 35(6), 1399-1413.

Noble, M., Wright, G., Dibben, C., Smith, G.A.N., McLennan, D., Antila, C., ......Lloyd, M. (2004). The English indices of deprivation 2004 (revised). Report to the Office of the Deputy Prime Minister. London: Neighbourhood Renewal Unit.

Paavola, L., Kunnari, S., \& Moilanen, I. (2005). Maternal responsiveness and infant intentional communication: Implications for the early communicative and linguistic development. Child: Care, Health and Development, 31(6), 727-735.

Papousek, M., \& von Hofacker, N. (1998). Persistent crying in early infancy: anon-trivial condition of risk for the developing mother-infant relationship. Child: Care, Health and Development, 24(5), 395-424. doi: 10.1046/j.1365-2214.2002.00091.x

Patterson, G. R., Reid, J. B., \& Dishion, T. J. (1992). Antisocial boys: Eugene, OR: Castalia.

Pauli-Pott, U., Mertesacker, B., \& Beckmann, D. (2004). Predicting the development of infant emotionality from maternal characteristics. Development and Psychopathology, 16(1), 19-42. doi: 10.1017/S0954579404040398

Pauli-Pott, U., Mertesacker, B., Bade, U., Bauer, C. \& Beckmann. (2000). Contexts of relations of infant negative emotionality to caregiver's reactivity/sensitivity. Infant Behavior and Development, 23(1), 23-39.

Paulussen-Hoogeboom, M. C., Stams, G. J. J., Hermanns, J., \& Peetsma, T. T. (2007). Child negative emotionality and parenting from infancy to preschool: A meta-analytic review. Developmental Psychology, 43(2), 438.

Pettit, G. S., \& Arsiwalla, D. D. (2008). Commentary on special section on "bidirectional parentchild relationships": The continuing evolution of dynamic, transactional models of 
parenting and youth behavior problems. Journal of Abnormal Child Psychology, 36(5), 711-718. doi: 10.1007/s10802-008-9242-8

Riese, M. L. (1987). Temperament Stability Between the Neonatal Period and 24 Months. Developmental Psychology, 23(2), 216-222.

Rodriguez, M. L., Ayduk, O., Aber, J. L., Mischel, W., Sethi, A., \& Shoda, Y. (2005). A contextual approach to the development of self-regulatory competencies: The role of maternal unresponsivity and toddlers' negative affect in stressful situations. Social Development, 14(1), 136-157.

Schumm, W. R., Nichols, C. W., Schectman, K. L., \& Grinsby, C. C. (1983). Characteristics of responses to the Kansas Marital Satisfaction Scale by a sample of 84 married mothers. Psychological Reports, 53, 567-572.

Seifer, R., Schiller, M., Sameroff, A. J., Resnick, S., \& Riordan, K. (1996). Attachment, maternal sensitivity, and infant temperament during the first year of life. Developmental Psychology, 32(1), 12-25.

Sharp, H., Pickles, A., Meaney, M., Abbott, K., Tibu, F., \& Hill, J. (2012). Frequency of infant stroking reported by mothers moderates the effect of prenatal depression on infant behavioural and physiological outcomes. PLoS One, 7, e45446. doi:10.1371/journal.pone.0045446.

Spitzer, R. L. and Endicott, J. (1975). Schedule for Affective Disorders and Schizophrenia Lifetime Version. New York: Biometrics Research.

Stams, G. J., Juffer, F., \& van Ijzendoorn, M. H. (2002). Maternal sensitivity, infant attachment, and temperament in early childhood predict adjustment in middle childhood: the case of 
adopted children and their biologically unrelated parents. Developmental Psychology, 38(5), 806-821.

Stein, A., Arteche, A., Lehtonen, A., Craske, M., Harvey, A., Counsell, N., \& Murray, L. (2010). Interpretation of infant facial expression in the context of maternal postnatal depression. Infant Behavior and Development, 33(3), 273-278.

Susman-Stillman, Amy, Kalkoske, Mark, Egeland, Byron, \& Waldman, Irwin. (1996). Infant temperament and maternal sensitivity as predictors of attachment security. Infant Behavior and Development, 19(1), 33-47. doi: http://dx.doi.org/10.1016/S0163$\underline{6383(96) 90042-9}$

Sutcliffe, A, Barnes, J, Belsky, J, Gardiner, J, \& Melhuish, E. (2012). Health of children born to older mothers in the UK. Archives of Disease in Childhood, 97(Suppl 1), A98-A99. doi: 10.1136/archdischild-2012-301885.233

Teasdale, J. D., \& Cox, S. G. (2001). Dysphoria: self-devaluative and affective components in recovered depressed patients and never depressed controls. Psychological Medicine, 31(07), 1311-1316.

Thompson, R. A. (1997). Sensitivity and Security: New Questions to Ponder. Child Development, 68(4), 595-597.

van den Boom, D. C., \& Hoeksma, J. B. (1994). The Effect of Infant Irritability on Mother-Infant Interaction: A Growth-Curve Analysis. Developmental Psychology, 30(4), 581-590. 
Table 1. Descriptive statistics and inter-correlations between the study variables.

\begin{tabular}{|c|c|c|c|}
\hline Variables & $\begin{array}{c}\text { Sensitivity to } \\
\text { Distress } \\
n=169\end{array}$ & $\begin{array}{c}\text { Sensitivity to } \\
\text { Non-Distress } \\
\quad n=260\end{array}$ & $\begin{array}{c}\text { Mean (SD) } \\
\text { or } \%\end{array}$ \\
\hline \multicolumn{4}{|l|}{ Outcome Variables } \\
\hline Sensitivity to Distress & -- & & $3.42(1.15)$ \\
\hline Sensitivity to Non-Distress & $.73^{* * *}$ & -- & $3.68(1.00)$ \\
\hline \multicolumn{4}{|l|}{ Stratification Variable } \\
\hline Psychological Abuse & $-.24^{* * *}$ & $-.16^{*}$ & $3.06(2.96)$ \\
\hline \multicolumn{4}{|l|}{ Contextual Factors } \\
\hline \multicolumn{4}{|l|}{ Marital Status } \\
\hline Married & $.21^{* *}$ & $.26^{* * *}$ & $41.40 \%$ \\
\hline Cohabiting & -.07 & -.09 & $33.10 \%$ \\
\hline Single & $-.17^{*}$ & $-.20^{* * *}$ & $25.20 \%$ \\
\hline Maternal Age & $.31^{* * *}$ & $.39^{* * * *}$ & $27.74(6.21)$ \\
\hline Deprivation Index & $-.24^{* * *}$ & $-.31^{* * *}$ & $32.23(20.38)$ \\
\hline Partner Satisfaction & $.15^{*}$ & $.19^{* *}$ & $4.75(1.38)$ \\
\hline \multicolumn{4}{|l|}{ Parent and Child Factors } \\
\hline DSM Major Depression Episode & -.04 & .03 & $15.10 \%$ \\
\hline Infant Irritability & -.06 & .01 & $3.61(1.61)$ \\
\hline
\end{tabular}

Note. $* * *=p<.001 ; * *=p<.01 ; *=p<.05$. 
Table 2. Multivariate multiple regression of maternal depression and infant irritability on maternal sensitivity to distress and nondistress

\begin{tabular}{|c|c|c|c|c|c|c|}
\hline \multirow[t]{2}{*}{ Variables } & \multicolumn{3}{|c|}{$\underline{\text { Sensitivity to Distress }}$} & \multicolumn{3}{|c|}{ Sensitivity to Non-Distress } \\
\hline & $B(\mathrm{SE})$ & $95 \% \mathrm{CI}$ of $B$ & $p$ value & $B(\mathbf{S E})$ & $95 \%$ CI of $B$ & $p$ value \\
\hline \multicolumn{7}{|l|}{ Stratification Variable } \\
\hline Psychological Abuse & $-.06(.03)$ & $-.10,-.02$ & .02 & $-.01(.02)$ & $-.04, .02$ & .56 \\
\hline \multicolumn{7}{|l|}{ Contextual Factors } \\
\hline Marital Status & $.02(.12)$ & $-.18, .17$ & .89 & $-.04(.09)$ & $-.17, .11$ & .69 \\
\hline Maternal Age & $.04(.02)$ & $.02, .06$ & .01 & $.05(.01)$ & $.03, .07$ & $<.001$ \\
\hline Deprivation Index & $-.01(.01)$ & $-.01, .00$ & .27 & $-.01(.00)$ & $-.01,-.00$ & $.06^{+}$ \\
\hline Partner Satisfaction & $.04(.01)$ & $-.06, .14$ & .53 & $.11(.05)$ & $.03, .19$ & .02 \\
\hline \multicolumn{7}{|l|}{ Maternal and Infant Factors } \\
\hline DSM depressive episode & $.18(.21)$ & $-.15, .51$ & .39 & $.27(.16)$ & $.00, .53$ & .09 \\
\hline Irritability & $-.01(.06)$ & $-.10, .10$ & .87 & $.05(.04)$ & $-.02, .12$ & .29 \\
\hline \multicolumn{7}{|l|}{ Interaction } \\
\hline \multicolumn{7}{|l|}{ Maternal Depression * } \\
\hline Infant Irritability & $-.46(.02)$ & $-.75,-.17$ & .01 & $-.19(.01)$ & $-.39,-.01$ & .09 \\
\hline
\end{tabular}

Note. ${ }^{+}=p$ significance level marginal; $\mathrm{CI}=$ confidence interval; $n=237$. 
Figure 1. Impact of maternal depression and infant irritability on maternal sensitivity to distress

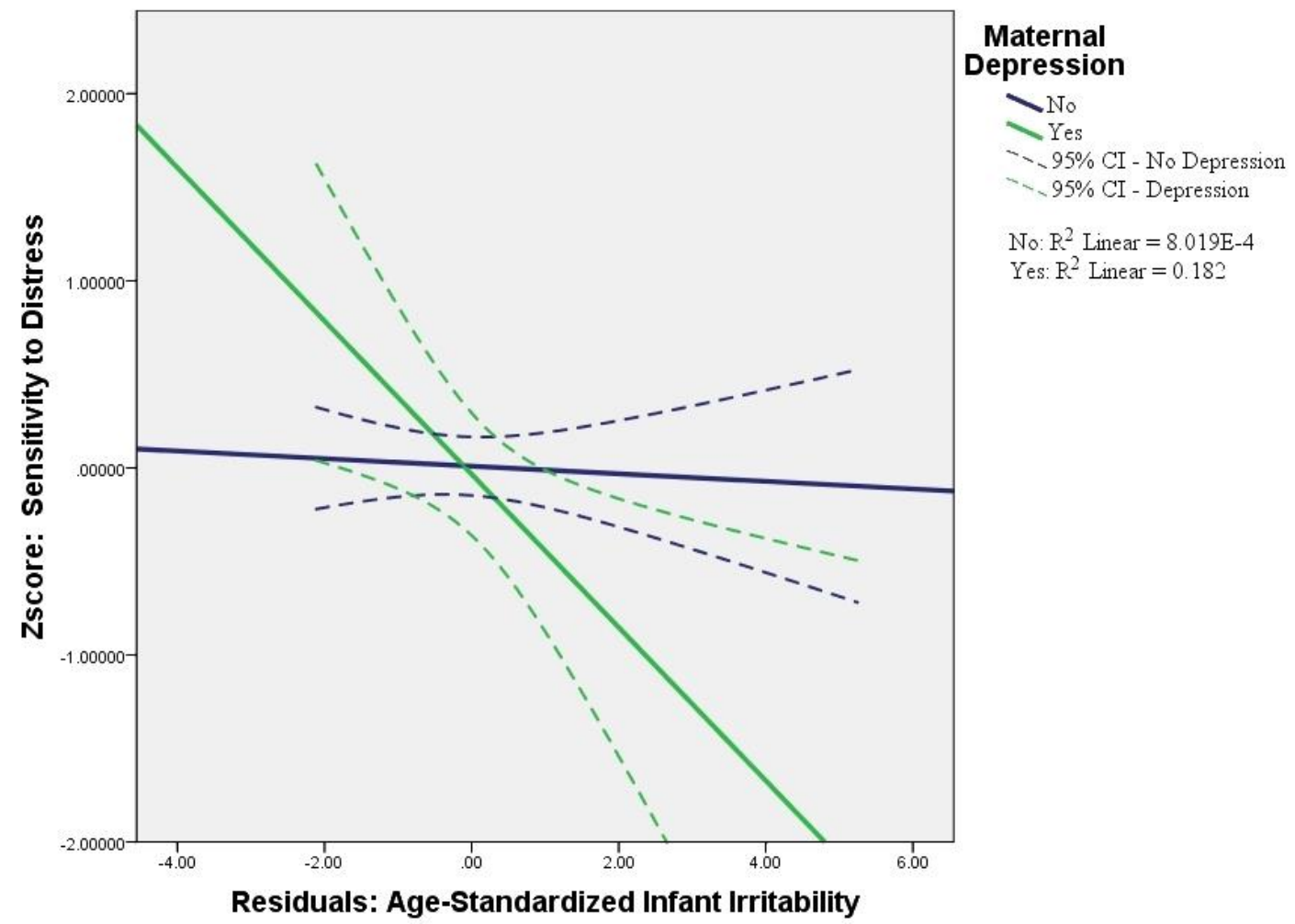

